\title{
Mechanical Behavior of AA6061 Aluminum in the Semisolid State Obtained by Partial Melting and Partial Solidification
}

\author{
E. GIRAUD, M. SUERY, and M. CORET
}

The tensile properties of a 6061 aluminum alloy have been studied in the semisolid state at large solid fractions. The tests have been carried out either after a partial melting treatment or after partial solidification. Results show the following: (1) the mechanical behavior depends on the liquid-phase distribution and, therefore, on the way the semisolid state has been achieved (melting or solidification); (2) there is a critical solid fraction range where the semisolid alloy is relatively brittle; and (3) the mushy alloy exhibits viscoplastic behavior with the occurrence of microsuperplasticity at low strain rate. Modeling of this behavior is carried out by considering either the area fraction of grain boundaries wetted by the liquid or a cohesion parameter of the solid phase, which depends on solid fraction and thermal treatment.

\section{INTRODUCTION}

THE aluminum alloy 6061 is used in many applications such as aeronautics, automotive industries, and architectural structures because of its versatility. ${ }^{[1]}$ This Al-Mg-Si alloy exhibits good corrosion resistance and high mechanical properties with appropriate thermal treatment. The strengthening (caused by aging treatments) results from precipitation of metastable phases from the supersatured Al-rich solid solution. Consequently, the treated alloy contains numerous submicronic particles, which represent obstacles to dislocation motion and, thus, cause hardening. ${ }^{[1]}$ However, these interesting properties can be modified during high-temperature forming processes and more particularly during welding and casting. This alloy, indeed, exhibits a great sensitivity to solidification defects such as porosity and hot cracking, which are very harmful for the subsequent mechanical properties of the alloy, thus limiting its use.

Hot cracking is a defect that initiates above the solidus temperature, i.e., in the semisolid state where liquid and solid phases coexist. It occurs in the last stages of solidification when the solid volume fraction is above 85 pct. $^{[2,3]}$ For these solid fractions, the solid phase forms a continuous and dense network of grains with the liquid phase remaining in the form of thin films and pockets. In the course of solidification, deformations (due to solidification shrinkage and thermal contraction) develop and exert tensile strains on remaining liquid films. Therefore, hot cracks initiate into the liquid phase and propagate through this phase in an intergranular manner, which can possibly lead to

E. GIRAUD, Ph.D. Student, and M. SUERY, Research Director, are with SIMaP, Universités de Grenoble, CNRS UMR5266, 38402 Saint Martin d'Hères Cedex, France. Contact e-mail: eliane.giraud@ simap.grenoble-inp.fr M. CORET, Associate Professor, is with LaMCoS, INSA-Lyon, CNRS UMR5259, 69621 Villeurbanne, France. fracture. ${ }^{[2,4]}$ It is now clear that the main reason for the occurrence of hot cracking is the inability of the material to accommodate strains at the very end of solidification. Thus, this phenomenon depends on the mechanical response of the mushy state together with the possibility for the liquid to flow to accommodate deformation of the solid network. It is then obvious that a better understanding of the occurrence of hot cracking requires a better knowledge of the rheology of the mushy alloy.

Essentially, three types of mechanical tests have been developed to study the rheological behavior of alloys in the semisolid state: tension, ${ }^{[2,4-10]}$ compression, ${ }^{[2,11]}$ and shear. ${ }^{[2,10]}$ Although the tensile test is the most difficult to perform owing to the very low strength and ductility of a semisolid alloy, it is the most interesting in the context of hot tearing since it allows testing the alloy in conditions close to those prevailing during the formation of this defect. However, to be really representative, the tensile test must be carried out during solidification, which is much more difficult than during partial melting. Indeed, in partial melting experiments, the material is initially solid so that heating can be performed by various means until the required liquid fraction is reached. If the liquid fraction is small enough, which is the case in hot tearing studies, the specimen keeps its original shape and the test can be carried out in a similar way as for a fully solid specimen. The situation is different for tests carried out during solidification. Indeed, the specimen must be initially liquid so that it requires holding in a mold to avoid liquid flow. The specimen can then be cast in the mold or a mold can be used to hold the liquid when the specimen is initially heated above its liquidus temperature. Experiments have been carried out according to these two procedures, and they have been used to develop both appropriate constitutive laws of the mushy state ${ }^{[2,6,12-14]}$ and criteria for hot cracking. ${ }^{[2,3,15-17]}$

In the present work, the tensile behavior of the AA6061 alloy has been investigated in the semisolid 
state by isothermal tensile tests. These tests have been carried out at various solid fractions and strain rates, following two different thermal paths: after partial melting or after partial solidification. These two paths have been studied because they are expected to lead to different liquid-phase distributions and, therefore, to different results in terms of rheological behavior. ${ }^{[6]}$ The other motivation of this work is that welding involves partial or complete melting followed by resolidification in the heat-affected zone and in the molten zone, respectively. The two paths are thus close to those encountered during welding, although there is no holding under isothermal conditions during this process.

\section{EXPERIMENTAL PROCEDURE}

\section{A. Studied Material}

The AA6061 alloy was supplied by ALMET as rolled plates, $50 \mathrm{~mm}$ in thickness and in the T6 condition (solution heat treated and then artificially aged). The composition is given in Table I.

Figure 1 shows the initial microstructure of the alloy in the rolling plane. Typical phases of Al-Mg-Si alloys are present: ${ }^{[18]} \mathrm{Mg}_{2} \mathrm{Si}$ (dark) and iron-rich phases (light). Other precipitates are also present, but they are not visible in the figure because of their small size. They result from the precipitation hardening induced by the T6 aging treatment.

\section{B. Tensile Tests}

Figure 2(a) shows the experimental device used for the tensile tests. An Adamel DY34 machine (MTS, Eden Prairie, MN) was employed for these tests. The force

Table I. Composition (Weight Percent) of the 6061 Alloy

\begin{tabular}{cccccc}
\hline $\mathrm{Mg}$ & $\mathrm{Si}$ & $\mathrm{Cu}$ & $\mathrm{Fe}$ & $\mathrm{Cr}$ & $\mathrm{Mn}$ \\
\hline 0.93 & 0.61 & 0.28 & 0.26 & 0.2 & 0.12 \\
\hline
\end{tabular}

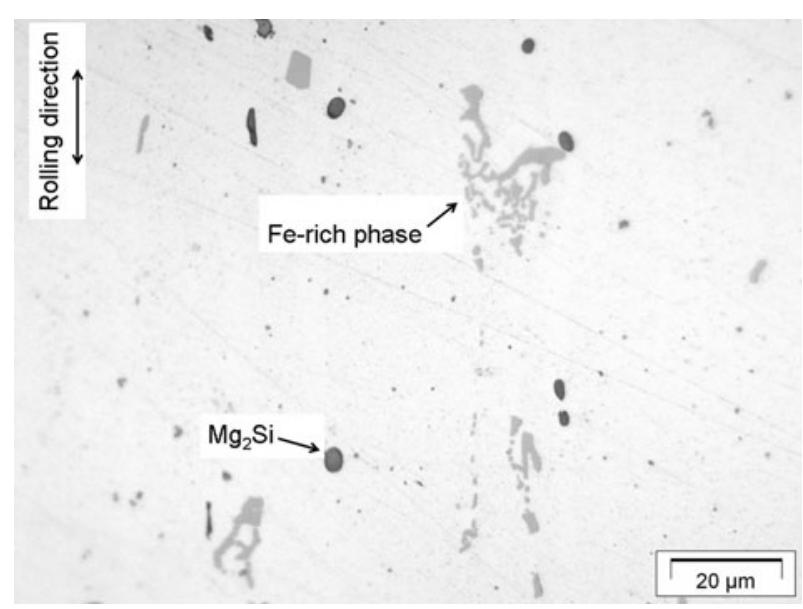

Fig. 1-Microstructure of the 6061 alloy in the rolling plane. was measured by a $2 \mathrm{kN}$ load cell. The displacement applied to the deformed zone of the specimen was determined from the crosshead displacement. The samples were cylinders of $9.5-\mathrm{mm}$ diameter and $120-\mathrm{mm}$ length. They were taken from the plates with their tensile direction parallel to the rolling direction. The central part of the sample was heated by induction at $2 \mathrm{~K} / \mathrm{s}$ until the desired temperature according to the scheduled thermal cycle. The temperature was measured by a K-type thermocouple of $0.5-\mathrm{mm}$ diameter located in the central part of the sample. It was monitored in real time to get close to the desired thermal cycle. An alumina crucible was placed around the heated zone to maintain the liquid in the center of the sample when very high liquid fractions are reached. A water flow was used on both sides of the heated zone to apply, when necessary, cooling rates ranging from 1 to $80 \mathrm{~K} / \mathrm{s}$. The temperature in the specimen, therefore, is not constant over its length. It is maximum in the central part of the specimen (corresponding to the test temperature), but it varies only by about $1 \mathrm{~K}$ over a length of $5 \mathrm{~mm}$ on either side of the center. This variation was determined by performing tests with specimens equipped with several thermocouples located at various distances from the central part.

Two different thermal paths were studied: after partial melting and after partial solidification. Figures 2(b) and (c) illustrate the corresponding thermal cycles. For partial melting, the sample was just heated (at $2 \mathrm{~K} / \mathrm{s}$ ) to the desired temperature. For partial solidification, the thermal cycle involves a transition from the solid to the liquid state followed by a cooling stage at a given rate until the desired temperature. Two cooling rates were studied: 1 and $20 \mathrm{~K} / \mathrm{s}$. In both types of experiments, the tensile test was conducted after a holding time of 30 seconds at the test temperature to reach a stationary temperature field in the specimen. Several tests were carried out to check that the holding time did not affect too much the microstructure and the resulting properties of the material in its semisolid state. It was found that a
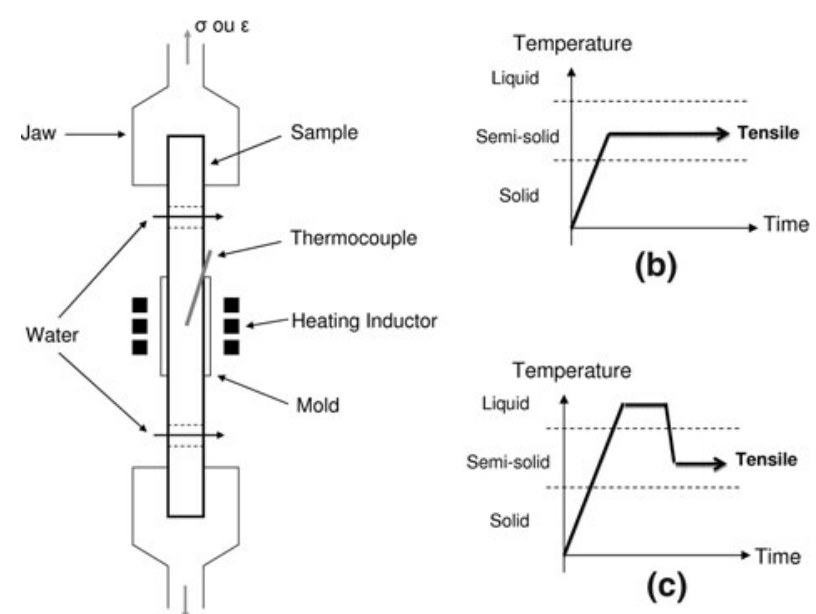

(b)

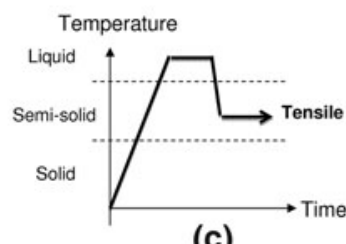

(a)

Fig. 2-Sketch $(a)$ of the experimental device used for the tensile tests and of the $(b)$ thermal cycles used in melting and $(c)$ solidification conditions. 
Table II. Temperature (Kelvin) and Corresponding Solid Fraction Used for the Tensile Tests

\begin{tabular}{lcc}
\hline Fs & $\begin{array}{c}\text { Temperature/ } \\
\text { Melting }\end{array}$ & $\begin{array}{c}\text { Temperature/ } \\
\text { Solidification }\end{array}$ \\
\hline 0.8 & 897 & 894 \\
0.9 & 881 & 873 \\
0.92 & 876 & 865 \\
0.94 & 869 & 863 \\
0.95 & 864 & 861 \\
0.96 & 859 & 858 \\
0.97 & 856 & 853 \\
0.98 & 852 & 843 \\
0.99 & 844 & 806 \\
1 & 828 & 779 \\
\hline
\end{tabular}

holding time of 30 seconds leads to an increase of stress of only $0.3 \mathrm{MPa}$ compared with cases without holding time, which is negligible.

Tensile tests were conducted at constant crosshead speeds of $0.01,0.1$, and $1 \mathrm{~mm} / \mathrm{s}$. The different test temperatures were linked to the solid fractions $(F s)$ by using the Alcan ProPhase software (Alcan CRV, Voreppe, France) (based on the diffusion model developed by Sigli et al ${ }^{[19]}$ ) with conditions adapted to each type of test. For melting, it was assumed that the material was in quasi-equilibrium conditions, so that a ProPhase calculation implemented at equilibrium taking into account solid diffusion was used. For solidification, the solid fractions were calculated for each cooling rate. For the highest cooling rate $(20 \mathrm{~K} / \mathrm{s})$, solid diffusion was neglected as predicted by a ProPhase calculation, since in this case, the solidification time was too short to allow for significant diffusion. Table II summarizes the test temperatures and the corresponding solid fractions. After the tensile tests, which were conducted until fracture, the fracture surfaces were observed by SEM.

\section{EXPERIMENTAL RESULTS}

Figure 3 shows typical stress-displacement curves obtained during tests carried out after partial melting at solid fractions of 0.94 and 0.99 . The same type of curves is obtained for tests performed after partial solidification. For the abscissa axis, displacement and not strain is used, since the length of the deformed zone during the test is not precisely known. For the ordinate axis, the stress is taken equal to the load divided by the initial section of the sample. Reproducibility is relatively good for both types of tests: an average standard deviation in stress of $0.7 \mathrm{MPa}$ was found for the same testing conditions. Since the scatter in stress is not so important, errors bars will not be shown in the following.

As shown in Figure 3, the stress increases until a peak and then decreases toward a nil value leading to some post peak ductility. Cracks are assumed to initiate at the peak stress: a low peak stress means that cracks can easily form. Post peak ductility corresponds to the displacement required for the stress to drop from its maximum value to zero. It defines the ability of the

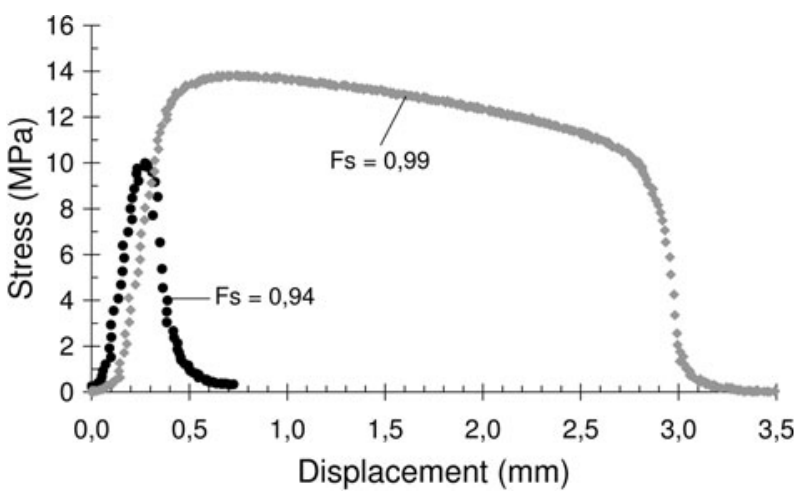

Fig. 3-Typical stress-displacement curves obtained during a tensile test carried out after partial melting at a displacement rate of $0.1 \mathrm{~mm} / \mathrm{s}$ and at solid fractions of 0.94 and 0.99 .

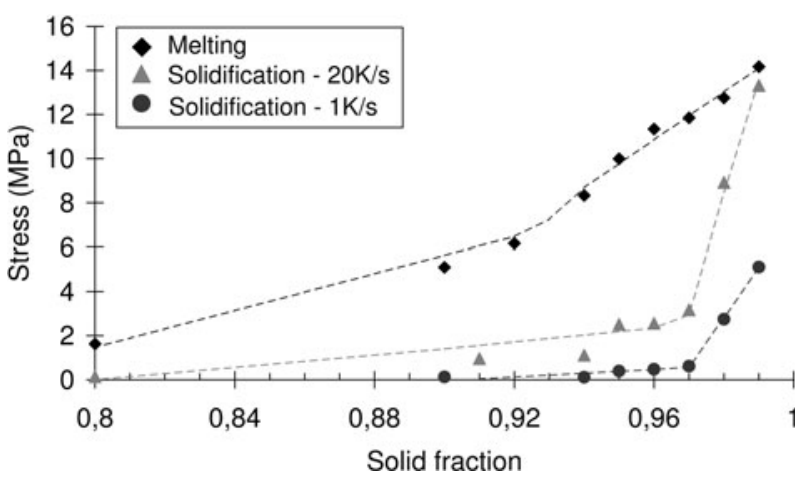

Fig. 4-Peak stress as a function of solid fraction at a displacement rate of $0.1 \mathrm{~mm} / \mathrm{s}$ for the tensile tests carried out under various conditions (melting, solidification with a cooling rate of 20 and $1 \mathrm{~K} / \mathrm{s}$ ).

mush to accommodate the imposed deformation, and therefore, it is an indication of the way cracks propagate in the material. Nearly zero post peak ductility corresponds to catastrophic failure, whereas a large value of the post peak ductility indicates that the cracks propagate in a more progressive manner. Note that post peak ductility can be only considered for sufficiently large solid fractions for which the solid skeleton can sustain tensile stresses. Peak stress and ductility depend on the considered solid fraction.

\section{A. Tensile Test after Partial Melting}

\section{Influence of solid fraction}

Tensile experiments were carried out at various temperatures in order to determine the influence of the solid fraction on the peak stress and on the post peak ductility. The displacement rate was $0.1 \mathrm{~mm} / \mathrm{s}$. Figure 4 shows that the peak stress decreases with decreasing solid fraction but with two different slopes: the variation of the peak stress with solid fraction is steeper at large solid fractions $(>0.93)$ compared to its variation at low solid fractions. An evolution of the microstructure is also visible in the fracture surfaces when solid fraction decreases: a larger proportion of dendrites is indeed present (Figure 5). 


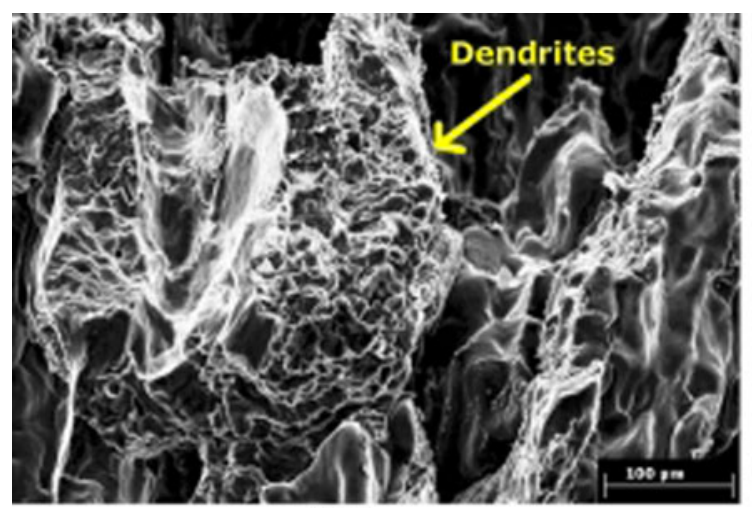

(a1)

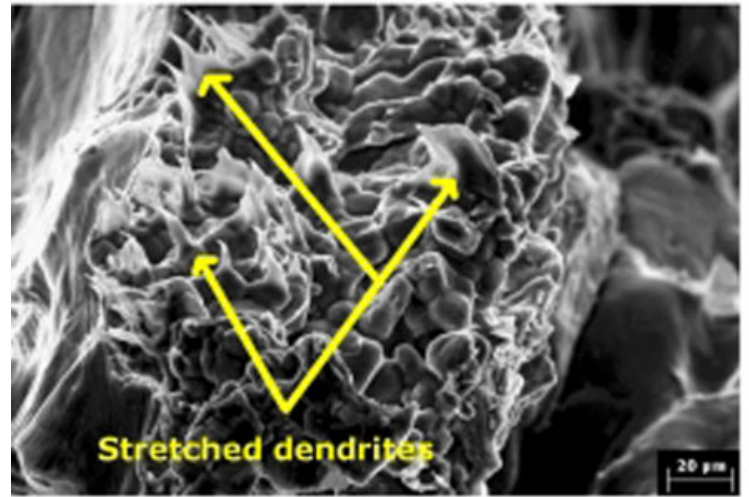

(a2)

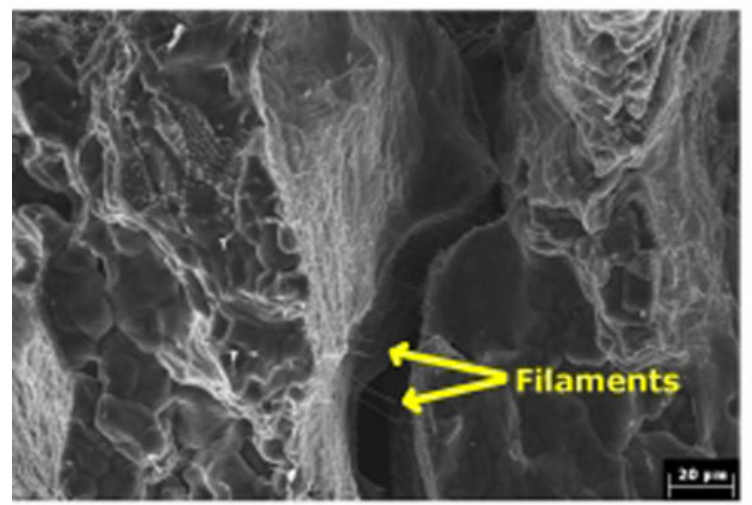

(a3)

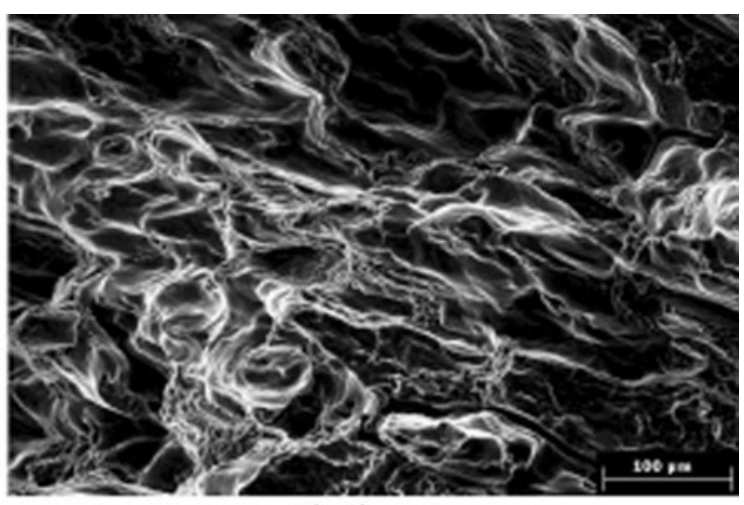

(b1)

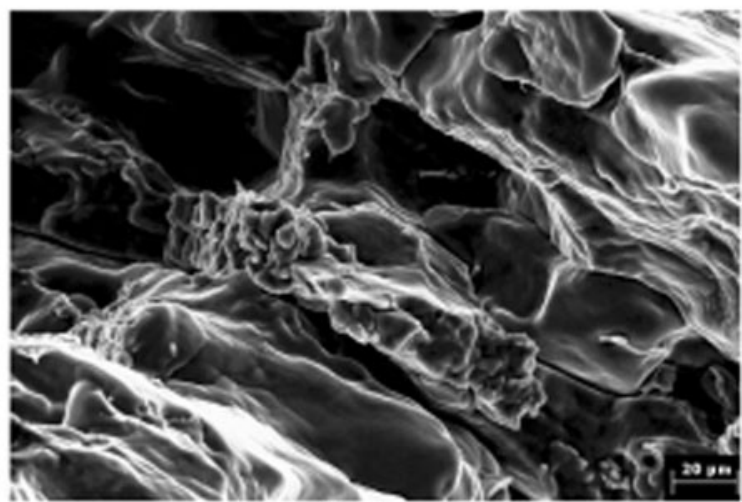

(b2)

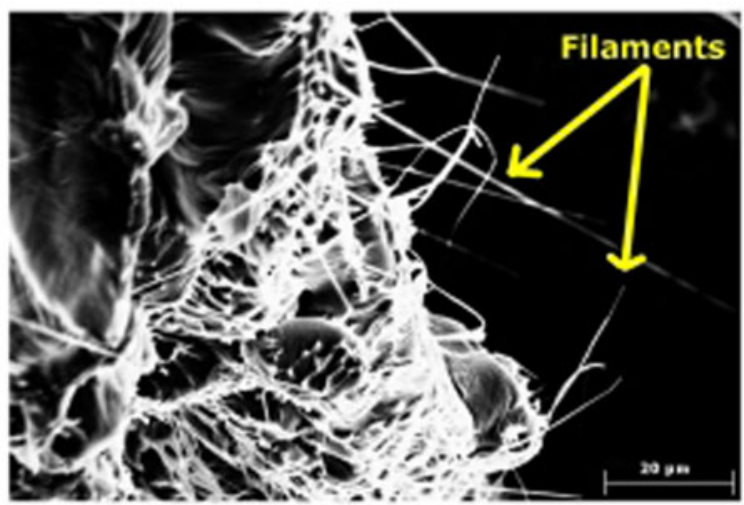

(b3)

Fig. 5-Fracture surfaces obtained after tensile tests carried out during melting at $F s=0.95(a)$ and $F s=0.97(b)$ with a displacement rate of $0.1 \mathrm{~mm} / \mathrm{s}(1,2)$ and $0.01 \mathrm{~mm} / \mathrm{s}(3)$.

Figure 6 shows the variation of the post peak ductility as a function of the solid fraction. The post peak ductility exhibits a minimum value for intermediate solid fractions $(0.90<F s<0.94)$ and very large values at both high and low solid fractions (in the studied range). The minimum ductility is observed in the solid fraction range for which a transition in the stress variation (Figure 4) from high slope to lower slope occurs. It should be noticed that the specimen at the lower tested solid fraction (i.e., $F s=0.8$ ) did not break so that its ductility is larger than that corresponding to the reported value. Therefore, the curve is in dashed form in this solid fraction range.

\section{Influence of displacement rate}

Figure 7 shows the variation of the peak stress as a function of the strain rate for three values of the solid fraction, $0.95,0.97$, and 0.99 . The strain rate was calculated by dividing the displacement rate by the length of the deformed zone. This length was assumed to be equal to $10 \mathrm{~mm}$, since the temperature does not vary by more than $1 \mathrm{~K}$ and the microstructure is homogeneous over this length. There is obviously some strain outside of this zone, but it is probably very limited since it was observed by testing specimens with several thermocouples that temperature drops (and, thus, solid fraction increases) quite significantly when moving away 


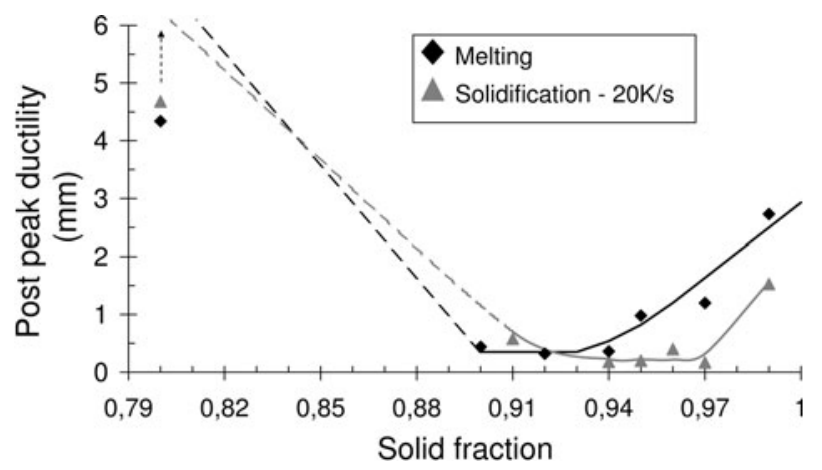

Fig. 6-Variation of the post peak ductility with solid fraction for melting and solidification conditions at a displacement rate of $0.1 \mathrm{~mm} / \mathrm{s}$.

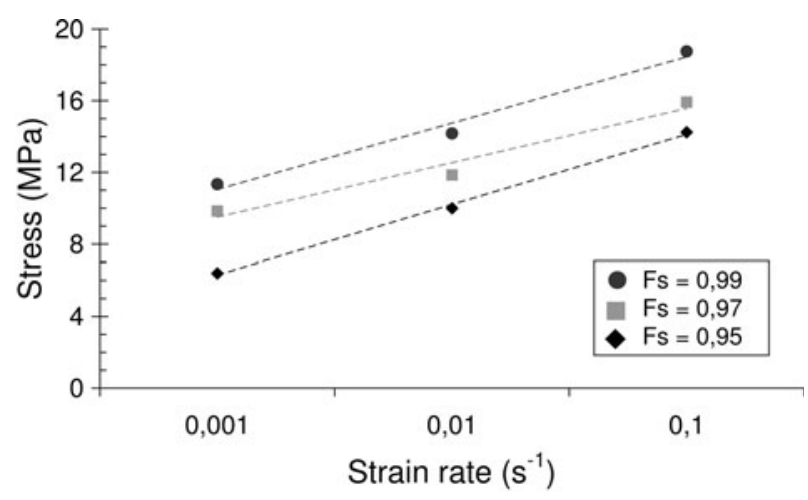

Fig. 7-Peak stress-strain rate curves obtained under partial melting conditions.

from this zone. Peak stress increases with increasing strain rate, indicating that the material exhibits viscoplastic behavior. The slope of the curves defines the strain rate sensitivity parameter $m$, which is close to 0.13 . It should be noted that considering a larger length of the deformed zone will simply shift the curves to smaller strain rates but not change their slopes.

The influence of the displacement rate on the post peak ductility is reported in Table III. It is found that the ductility increases with increasing displacement rate whatever the solid fraction. This variation is rather surprising since an increase of the strain rate leads generally to less ductility.

Changing the displacement rate over the range from 0.1 to $1 \mathrm{~mm} / \mathrm{s}$ has a significant impact on the fracture surfaces. As shown in Figure 5, at low displacement rate, long and thin filaments are present and they disappear when the displacement rate increases. The filaments are present on fracture surfaces for all tested solid fractions at the lowest displacement rate, but Figure 5 shows the fracture surface at two solid fractions only.

\section{B. Tensile Tests after Partial Solidification}

\section{Influence of solid fraction}

In a similar way as for tests carried out after partial melting, tensile tests were performed at various temperatures after partial solidification at a displacement rate of $0.1 \mathrm{~mm} / \mathrm{s}$. Figure 4 shows the variation of the peak stress as a function of solid fraction. Peak stress obviously increases with increasing solid fraction. At a solid fraction of 0.97 , the peak stress-solid fraction curve exhibits a transition. Below 0.97, peak stress increases very slowly with increasing solid fraction and remains very small. At higher solid fractions, peak stress increases much more rapidly. This transition results also in an evolution of the microstructure, as shown in Figure 8, with dendrite deformation at the largest solid fractions.

The curve obtained for the tests carried out after partial solidification exhibits the same shape as for the tests carried out after partial melting. However, as a general observation, the peak stress values are smaller in the case of solidification. This is particularly true in the intermediate solid fraction range, whereas at 0.8 and 0.99 , the peak stresses are very close. It is also observed that the transition from low slope to higher slope is shifted to larger solid fraction compared to partial melting experiments.

The variation with solid fraction of the post peak ductility is shown in Figure 6. A minimum ductility is again found in the intermediate solid fraction range $(0.94<F s<0.97)$. Compared with experiments carried out after partial melting, this range corresponds to larger solid fractions. At low solid fraction and at 0.99, the post peak ductility is roughly identical for the two types of experiments.

\section{Influence of displacement rate}

Figure 9 shows the variation of the peak stress as a function of strain rate calculated from the displacement rate with a length of the deformed zone equal to $10 \mathrm{~mm}$. As for experiments carried out after partial melting, peak stress increases with increasing strain rate except at

Table III. Variation of Post Peak Ductility (Millimeters) with Displacement Rate and Solid Fraction for the Two Thermal Paths

\begin{tabular}{lcccc}
\hline Type of Test & $F s$ & $\begin{array}{c}\text { Post Peak Ductility }(\mathrm{mm}) \\
\text { at } 0.01 \mathrm{~mm} / \mathrm{s}\end{array}$ & $\begin{array}{c}\text { Post Peak Ductility (mm) } \\
\text { at } 0.1 \mathrm{~mm} / \mathrm{s}\end{array}$ & $\begin{array}{c}\text { Post Peak Ductility (mm) } \\
\text { at } 1 \mathrm{~mm} / \mathrm{s}\end{array}$ \\
\hline Melting & 0.95 & 0.6 & 0.98 & 1.24 \\
& 0.97 & 1.03 & 2.73 & 1.81 \\
Solidification & 0.99 & 2.24 & 0.2 & 0.32 \\
& 0.95 & 0.14 & 0.17 & 0.37 \\
& 0.97 & 0.12 & 1.53 & 1.72 \\
\hline
\end{tabular}




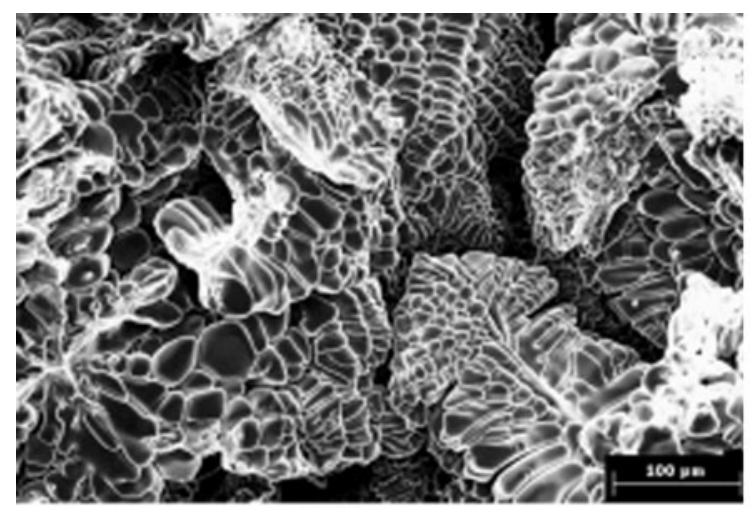

(a1)

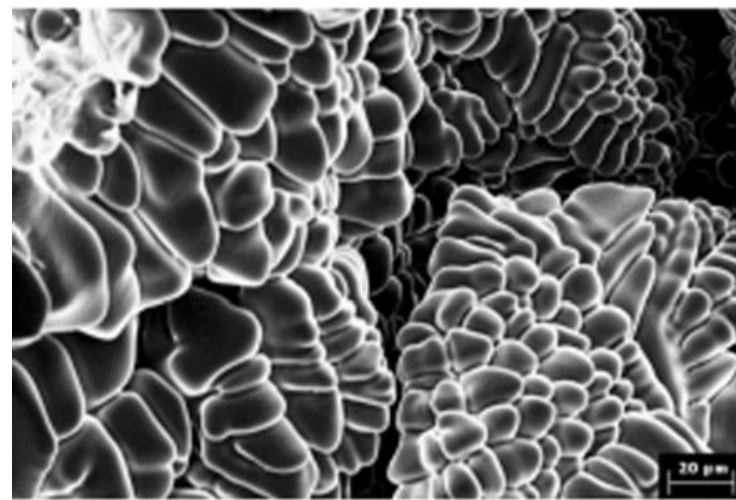

(a2)

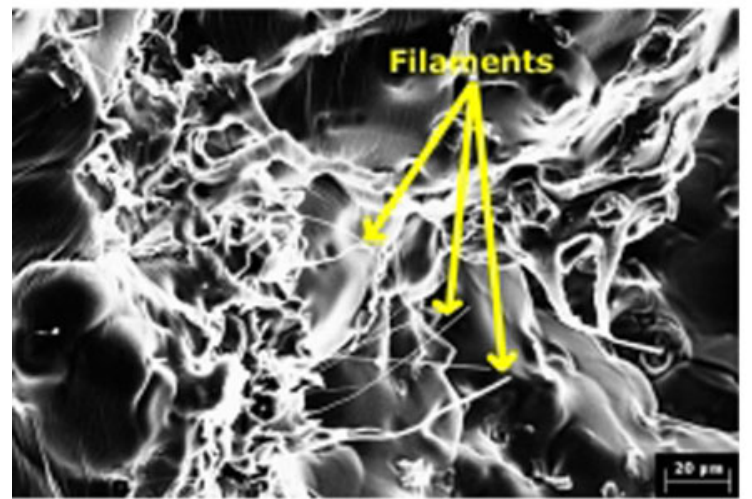

(a3)

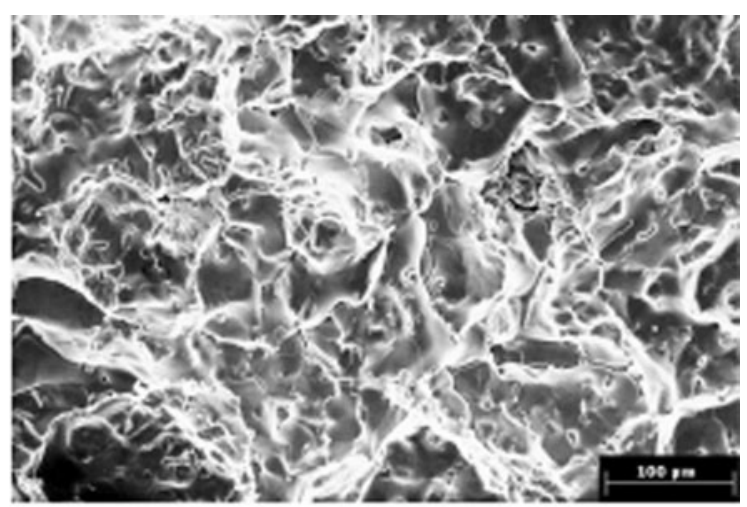

(b1)

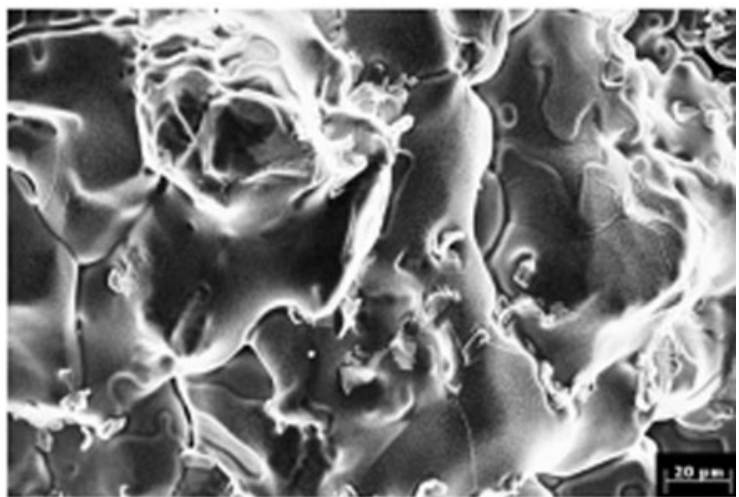

(b2)

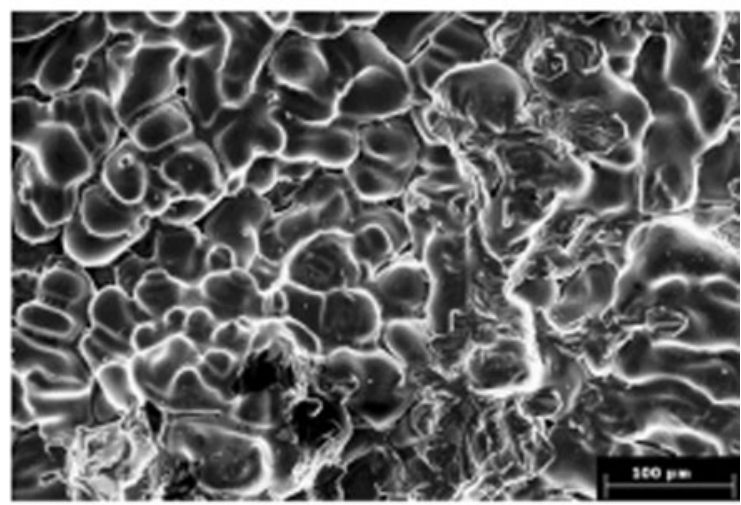

(c)

Fig. 8-Fracture surfaces obtained after tensile tests carried out during solidification at $F s=0.95(a, c)$ and $F s=0.99(b)$ with a displacement rate of $0.1 \mathrm{~mm} / \mathrm{s}$ and a cooling rate of $20 \mathrm{~K} / \mathrm{s}(1,2), 0.01 \mathrm{~mm} / \mathrm{s}$ and $20 \mathrm{~K} / \mathrm{s}(3)$, and $0.1 \mathrm{~mm} / \mathrm{s}$ and $1 \mathrm{~K} / \mathrm{s}$ (c).

a solid fraction of 0.97 . At 0.95 and 0.99 , viscoplastic behavior is observed with a strain rate sensitivity parameter $m$ close to 0.17 . The reason for this different behavior at 0.97 is not known, but it corresponds to the transition observed in the peak stress-solid fraction curve. A similar behavior at the same solid fraction was observed by Fabrègue et al. in the case of a 6056 alloy. ${ }^{[6]}$ The values of the post peak ductility obtained at the various displacement rates are reported in Table III. Again, ductility increases with increasing displacement rate, but the effect is less significant than in the case of partial melting experiments. As for partial melting experiments, thin filaments are present on the fracture surfaces (Figure 8) for the lowest displacement rate. This phenomenon occurs at low strain rate for each tested solid fraction.

\section{Influence of cooling rate}

The previous results were obtained after partial solidification performed at a cooling rate of $20 \mathrm{~K} / \mathrm{s}$. Experiments were also carried out at a cooling rate of $1 \mathrm{~K} / \mathrm{s}$, and Figure 4 shows the variation of the peak stress as a function of the solid fraction. The peak stress evolves in a similar way as for a cooling rate of $20 \mathrm{~K} / \mathrm{s}$, but the stress values are lower. There is still a transition in the curve at a solid fraction of 0.97 , indicating that 


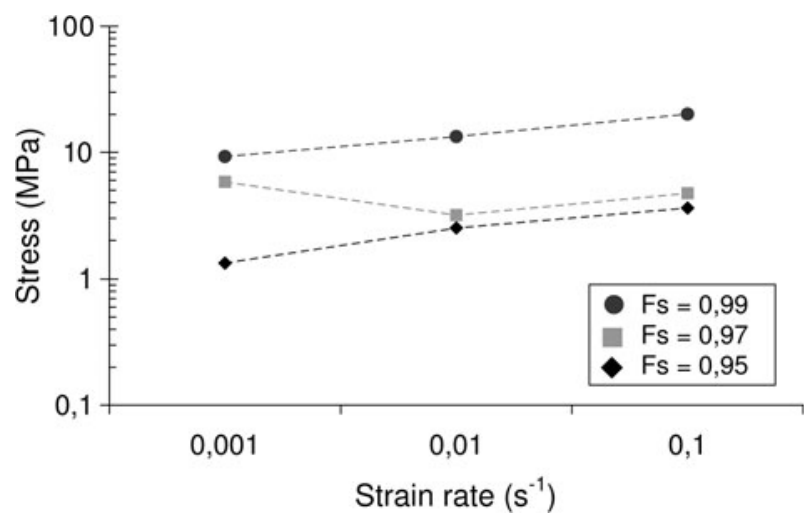

Fig. 9-Peak stress-strain rate curves obtained under partial solidification conditions.

the occurrence of dendrite deformation seems to be not influenced by the cooling rate. Concerning the evolution of the post peak ductility, the data are not shown since the reached values are too low to be correctly differentiated from the artefacts.

\section{DISCUSSION}

The isothermal tensile behavior of the alloy in the mushy state at large solid fractions generated after partial melting will be discussed first. Then the behavior observed after partial solidification will be examined and comparison between the two modes will be performed. These behaviors will be modeled thereafter by considering the variation of the area fraction of grain boundaries wetted by the liquid and of the cohesion of the solid network as functions of solid fractions. Finally, the presence of filaments on fracture surfaces will be discussed, since it has been observed in the two types of experiments.

\section{A. Behavior of Mushy State in Melting Conditions}

When solid fraction decreases upon partial melting, it was found from tensile experiments carried out isothermally at constant displacement rate that the peak stress decreases (Figure 4) and the post peak ductility exhibits a minimum for intermediate solid fractions (Figure 6). It is commonly accepted that these variations are directly linked to the evolution of the liquid distribution. ${ }^{[2,3]}$ Twite et $a l^{[5]}$ explained, in detail, that changes in liquidphase morphology occur following a specific sequence: (1) discontinuous liquid appears at triple boundaries, (2) liquid pockets spread along grain boundaries, and (3) continuous liquid films form. This evolution of morphology has been observed also by Chu et al ${ }^{[7]}$ and van Haaften et al..$^{[4]}$ by considering the evolution of the fracture surfaces, which exhibit (1) solid bridges at high solid fractions, (2) a mixture of solid bridges and liquid films, and (3) only liquid films. This evolution of the liquid distribution corresponds to an increase of the fraction of grain boundaries covered by the liquid, as defined by Reference 8 .
The critical solid fraction $(0.93)$ for which a transition is observed in the peak stress-solid fraction curve (Figure 4) corresponds to the transition between discontinuous (pockets) and continuous (films) liquid distribution. For $F s>0.93$, only liquid pockets are present and, thus, numerous solid-solid contacts too. Because solid bridges are more resistant than liquid films in a semisolid material and allow deformation in a ductile manner, peak stress and ductility are large. This means that, in this solid fraction range, crack formation and propagation are quite difficult since it is necessary to break solid bridges. The occurrence of solid coalescence within this solid fraction range is confirmed by the presence of numerous stretched dendrites on the fracture surfaces, as shown in Figure 5. When solid fraction decreases toward 0.93 , the volume of liquid pockets increases so that liquid starts spreading along grain boundaries. Solid-solid contacts become less numerous so that peak stress drops. For $F s<0.90$, continuous liquid films are present. The mushy alloy, thus, exhibits relatively low strength but high ductility. Indeed cracks can easily initiate in the liquid films, but sufficient liquid is available and the permeability of the solid network becomes large enough to heal cracks and delay fracture. This type of behavior has been highlighted by Terzi et al. ${ }^{[20]}$ with in-situ X-ray tomography observations. They reported that, at the onset of deformation, the liquid is homogeneously distributed between the grains. Then, during deformation, an accumulation of liquid occurs in the deformed zone, which thus confirms that liquid flows toward regions in expansion. As shown in Figure 6, there is a solid fraction range ( 0.90 to 0.94 ), where a minimum ductility is observed. In this range, solid-solid contacts are not sufficiently developed to hinder crack formation or propagation, and liquid films are too thin and discontinuous to allow crack healing. This scenario has been reported again by Terzi et al.:.[20] when liquid feeding is no longer possible, a pore nucleates and propagates in the liquid phase. Thus, in the mushy state, under melting conditions, there is a critical solid fraction range where the material is relatively brittle and where the risk of hot cracking should be very high.

This variation of the peak stress (with two different slopes) and ductility (with a minimum for intermediate solid fractions) has been reported already in the literature. $^{[2,6,15]}$ It corresponds to a ductile/brittle/ductile transition in the fracture mode of the mushy state. ${ }^{[2]}$ Fabrègue et al. ${ }^{[6]}$ studied an AA6056 alloy and found the same variations in stress and ductility. However, the critical solid fraction was larger (close to 0.97) and the brittle range was shifted toward higher solid fractions too. This difference can be linked to the alloy, which is different from the one used in the present work, and possibly to the heating rate of the specimen and to the holding time before testing. Indeed, Fabrègue used a heating rate of $25 \mathrm{~K} / \mathrm{s}$ and a holding time of 5 seconds so that, under these conditions, microstructural evolution has been probably very limited. Therefore, the microstructure investigated after partial melting was not very different from that formed during partial solidification. The solid fraction at the transition is indeed close 
to that reported in this work for partial solidification. Fabrègue observed a difference in peak stress between partial melting and partial solidification, but the difference is smaller than in the present work, confirming that the conditions of partial melting have led to a microstructure consisting of a larger proportion of liquid films more similar to a solidification microstructure.

In the present work, the heating rate was $2 \mathrm{~K} / \mathrm{s}$ and a holding time of 30 seconds was applied before testing. Under these conditions, the microstructure is very different from that formed during solidification, leading to a large difference of behavior, as will be discussed later.

The strain rate influences the peak stress according to a stress exponent $n$ close to $8(n=1 / \mathrm{m}=1 / 0.13)$. This value indicates that the mushy alloy exhibits viscoplastic behavior in this range. The value of the exponent is quite high compared to the usual values for the deformation of a solid at high temperature. Fabrègue et al. ${ }^{[6]}$ reported even larger values $(\sim 15)$. No explanation has been given for these high values.

Strain rate also has an influence on the post peak ductility (Table III): increasing the strain rate leads to an increase of the post peak ductility. This type of influence is rather surprising: an increase of the strain rate leads usually to a smaller ductility since less time is given to the accommodation processes. A possible explanation can be found by considering the zone of the specimen adjacent to fracture for the two displacement rates, $0.01 \mathrm{~mm} / \mathrm{s}$ and $1 \mathrm{~mm} / \mathrm{s}$ (Figure 10). At $0.01 \mathrm{~mm} / \mathrm{s}$, the zone is almost free of cracks, which indicates that deformation was highly localized leading to a small displacement to fracture. Conversely, at $1 \mathrm{~mm} / \mathrm{s}$, deformation was less localized with many cracks present in this zone. As a consequence, the post peak ductility is larger, as observed experimentally.

\section{B. Behavior of Mushy State in Solidification Conditions}

When solid fraction increases during partial solidification, it was found from tensile experiments carried out isothermally at constant displacement rate that the peak stress increases and the post peak ductility exhibits a minimum for intermediate solid fractions. During conventional solidification, the solid develops in the form of dendrites so that the liquid is basically located in the interdendritic spaces. Its morphology therefore changes as solidification proceeds. ${ }^{[2,17,21]}$ At the beginning, the dendrites are free to move in the liquid and liquid flow is also very easy. When the dendrites begin to come into contact (at coherency solid fraction), liquid surrounds the dendrites and can circulate between the dendrite arms to accommodate deformation. Then the solid skeleton becomes more and more dense, hindering the flow of the liquid phase, which still wets the dendrite arms in the form of thin films. Beyond the coalescence solid fraction, the surface area of solid-solid contact increases rapidly and only isolated liquid pockets remain until solidification is completed.

The transition solid fraction of 0.97 observed in the peak stress-solid fraction curve corresponds to the transition between a mechanical behavior controlled by liquid films and a behavior controlled by solid bridges. Such a value of the solid fraction is often reported in the literature as the typical value for coalescence in aluminum alloys. ${ }^{[2,6,21]}$ For large solid fractions $(>0.97)$, the behavior is controlled by the solidsolid contacts. The material response is close to that of a solid tested at high temperatures so that strength and ductility are large; thus, crack formation and propagation are quite difficult. For low solid fractions $(<0.94)$, the strength is mainly due to liquid films that are developed enough to heal initiated cracks and delay fracture. Thus, the strength is low but the ductility is large. However, for solid fractions close to the critical one, (i.e., 0.94 to 0.97 ), the mushy alloy is in a critical situation where solid bridges are not developed enough to stop crack propagation, but are sufficiently developed to hinder liquid flow. Consequently, the material shows a relatively brittle behavior (i.e., a minimum ductility) within this solid fraction range, which should correspond to great sensitivity to hot cracking.

Similar to the behavior observed during partial melting, the alloy exhibits viscoplastic behavior with a

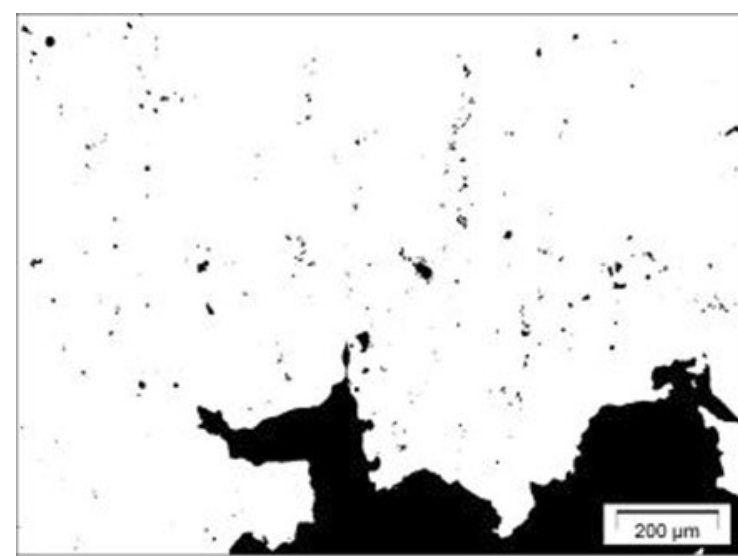

(a)

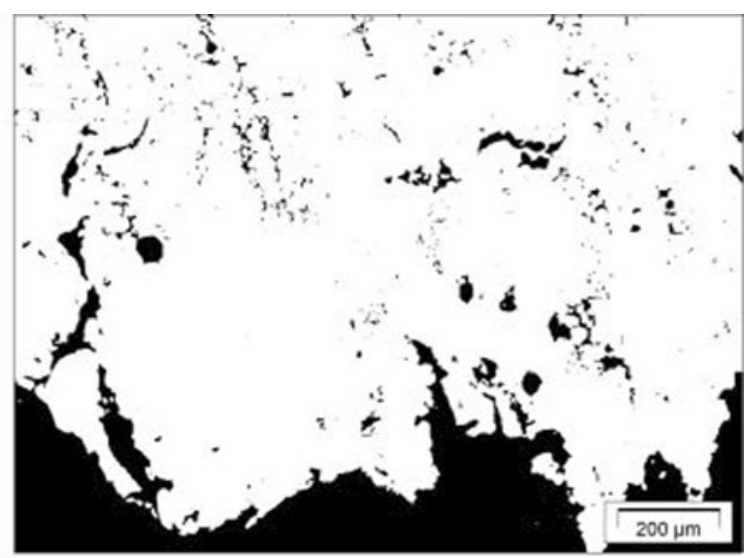

(b)

Fig. 10-Microstructure in the heated zone close to fracture after a tensile test carried out during partial melting at $F s=0.97$ and for a displacement rate of $(a) 0.01 \mathrm{~mm} / \mathrm{s}$ and $(b) 1 \mathrm{~mm} / \mathrm{s}$. The pictures are in black and white to clearly show the cracks (black). 
stress exponent close to $6(n=1 / m=1 / 0.17)$. This value is again larger than that found for hightemperature deformation of a solid. This could come from the limited number of experiments that have been carried out. Although the experiments are fairly reproducible, a small scatter in the stress level could lead to a slightly different $n$ value in better agreement with values usually reported during high-temperature deformation.

As for partial melting, higher strain rates lead to larger post peak ductility. The same explanation can be expressed: at low strain rate, the deformation is highly localized, which leads to a more brittle behavior compared with high strain rate deformation.

Finally, the rheological behavior at high solid fractions depends on the cooling rate applied during solidification of the alloy, as shown in Figure 4. Although the general trend is the same (increase of peak stress with increasing solid fraction, transition at the same solid fraction), a coarse microstructure, obtained by using a low cooling rate, exhibits a lower strength than that of a fine-grained one (obtained by using a higher cooling rate). In a fine-grained microstructure, the liquid is distributed around the dendrite arms in a more homogeneous manner. The liquid films are then thinner, thus leading to a larger strength according to Laplace's law. This explanation holds when liquid films are still present. However, at a solid fraction of 0.99 , the liquid is assumed to be distributed only in the form of pockets located at triple grain boundaries. The strength of the two alloys, therefore, should be identical, which is not observed: the coarse-grained alloy still exhibits a lower strength for this solid fraction. This behavior may be linked to the lower ductility of the coarse-grained alloy. Indeed, for this material, the maximum stress is reached after a smaller displacement than for the fine-grained alloy. Fracture starts to occur earlier so that the peak stress is reduced.

\section{Comparison of Mechanical Behavior in Melting and Solidification Conditions}

The two thermal paths used to study the tensile behavior of the semisolid AA6061 alloy lead to different mechanical responses for intermediate solid fractions, i.e., in the range $[0.80$ to 0.99$]$. For $F s \geq 0.99$, the liquid fraction is so small that it is assumed that for both paths it is present in the form of isolated liquid pockets surrounded by solid-solid contacts. In this case, the semisolid alloy behaves as a solid tested at high temperatures with similar strength and ductility. For $F s$ close to 0.80 , the microstructure and, therefore, the properties are also very similar and consist of solid grains wetted by thick liquid films that control the mechanical response. Strength is small and ductility is quite large, since liquid flow can easily heal forming cracks. For intermediate solid fractions, the microstructure depends on the thermal path. For melting, the liquid phase spreads along grain boundaries only when solid bridges start melting. For solidification, the liquid is initially present and it is rejected at grain boundaries by the dendrite growth until solid bridges form. Therefore, it is obvious that, for the same solid fraction, more liquid will be present as films along grain boundaries in a partially solidified microstructure than in a partially melted microstructure. The strength is, thus, lower for solidification than for melting. With the same explanation, the minimum ductility range occurs at higher solid fractions in the case of solidification, since liquid films are present up to larger solid fractions. The fracture surfaces, shown in Figures 5 and 8, illustrate the differences in microstructure within the intermediate solid fraction range. A ductile fracture surface with some isolated dendrites can be seen in melted specimens and a smooth fracture surface with only dendrites in solidified specimens.

\section{Modeling of the Tensile Behavior}

The tensile behavior of the semisolid AA6061 alloy at very large solid fractions is viscoplastic with strain rate sensitivity parameters not very different from those corresponding to the high-temperature deformation of a solid. Therefore, it is assumed that the behavior is controlled by the solid phase. However, even a small amount of liquid reduces considerably the tensile strength, which cannot be modeled by considering simply the liquid as pores. Indeed, the liquid can be in the form of thin films that wet the grain boundaries so that the load will be supported by the solid network only.

Based on this assumption, van Haaften et al. ${ }^{[8]}$ have proposed the following equation to describe the rheological behavior of a semisolid alloy:

$$
\dot{\varepsilon}=A \times\left(\frac{\sigma}{1-F_{\mathrm{LGB}}}\right)^{n} \times \exp \left(-\frac{Q}{\mathrm{R} T}\right)
$$

where $\sigma$ is the flow stress, $\dot{\varepsilon}$ the strain rate, $n$ the stress exponent, $Q$ an activation energy, $A$ a constant, $\mathrm{R}$ the gas constant, $T$ the temperature, and $F_{\mathrm{LGB}}$ the area fraction of grain boundaries covered by liquid.

Another way to consider the influence of the liquid is to assume that the cohesion of the solid network is reduced by the presence of liquid. A model based on this concept has been established by Ludwig et al. ${ }^{[12]}$ In their model, the plastic strain rate tensor of the solid phase for the partially cohesive mush is given by

$$
\dot{\varepsilon}_{S}^{P}=\frac{\dot{\varepsilon}_{0}}{\left(C s_{0}\right)^{n}}\left\{-\frac{A_{2}}{3} \bar{P}_{S} 1+\frac{3}{2} A_{3} S_{S}\right\}\left\{A_{2} \bar{P}_{S}^{2}+A_{3} \bar{\sigma}_{S}^{2}\right\}^{\frac{n+1}{2}}
$$

where $C$ is the cohesion of the solid; 1 the unit tensor; $\bar{P}_{S}$ the effective pressure on the solid skeleton; $\bar{\sigma}_{S}$ the Von Mises stress; $S_{S}$ the solid phase deviatoric effective stress tensor; $A_{2}$ and $A_{3}$ solid fraction functions; and $n, \dot{\varepsilon}_{0}$, and $s_{0}$ material parameters in the fully solid state. $A_{2}$ and $A_{3}$ are solid fraction functions, which account for the softening effect of the liquid in the form of pockets. The presence of liquid films leads to an additional softening effect through the cohesion parameter $C$.

Whatever the considered model, the evolution of the liquid distribution with solid fraction is taken into account through internal variables such as $F_{\text {LGB }}$ for van Haaften's model and $C$ for Ludwig's model. Our objective in this modeling part is to propose a variation 
of these two variables with solid fraction under melting and solidification conditions.

\section{Variation of $F_{L G B}$}

By assuming tetrahedral liquid pockets and perfect wettability of the solid by the liquid, Wray ${ }^{[24]}$ related the values of $F_{\mathrm{LGB}}$ to the liquid fraction (below 0.1 ). These values are given in Table IV. They were used successfully by References 6 and 8 to predict the variation of the measured peak stress with solid fraction.

For the determination of the material parameters $A$, $Q$, and $n$, the results of the tensile tests carried out at the solidus temperature were used. The value of $Q$ has been taken at $133 \mathrm{~kJ} / \mathrm{mol}$, which is an average value of the activation energy for the diffusion in aluminum. ${ }^{[22,23]}$ Table $\mathrm{V}$ gives the values of the material parameters for the two types of tensile experiments.

By inserting the $F_{\text {LGB }}$ values (Table IV) and the material parameters (Table V) in Eq. [1], a bad agreement is obtained between the predicted and the experimental results for the melting and solidification conditions. As shown in Figure 11, the variation of the peak stress with solid fraction is overestimated in the solidification case and underestimated in the melting case. This disagreement can be attributed to a liquid morphology different from that assumed by Wray.

Consequently, a new relationship relating $F_{\mathrm{LGB}}$ to the liquid fraction is determined in order to reproduce the stress variation measured during the tests. The $F_{\mathrm{LGB}}$ values, therefore, are determined from Eq. [1] by using the experimental values for the stress and the data given in Table $\mathrm{V}$ for the material parameters. Figure 12 gives the variations of $F_{\mathrm{LGB}}$ with solid fraction. The different curves show that the fraction of grain boundaries wetted by the liquid is smaller after partial melting than after partial solidification and thus underline the differences in the liquid distribution between the two thermal paths.

Table IV. Area Fraction of Grain Boundaries Wetted by the Liquid $\left(F_{\mathrm{LGB}}\right)$ as a Function of the Liquid Fraction According to Wray ${ }^{[24]}$

\begin{tabular}{ll}
\hline Liquid Fraction & $F_{\mathrm{LGB}}$ \\
\hline 0.01 & 0.2 \\
0.02 & 0.4 \\
0.03 & 0.5 \\
0.04 & 0.59 \\
0.05 & 0.65 \\
0.06 & 0.7 \\
0.07 & 0.73 \\
0.08 & 0.78 \\
0.09 & 0.8 \\
0.1 & 0.83 \\
\hline
\end{tabular}

Table V. Values of the Material Parameters for Equation [1]

\begin{tabular}{lccr}
\hline Type of Test & $A\left(\mathrm{MPa}^{-n} \cdot \mathrm{s}^{-1}\right)$ & $Q(\mathrm{~kJ} / \mathrm{mol})$ & $n$ \\
\hline Melting & $4.4 \cdot 10^{-5}$ & 133 & 8 \\
Solidification & $1.6 \cdot 10^{-1}$ & 133 & 6 \\
\hline
\end{tabular}

\section{Variation of $C$}

In the same way as for $F_{\mathrm{LGB}}$, the variation of $C$ is determined from Eq. [2] using the experimental stress values. For the determination of the material parameters $\left(n, \dot{\varepsilon}_{0}\right.$, and $\mathrm{s}_{0}$ ), the results of the tensile tests carried out at $F s=0.99$ were used. The initial state (to calculate material parameters) is not considered at $F_{S}=1$ as for $F_{\text {LGB }}$, since, according to Ludwig, ${ }^{[12]}$ the semisolid alloy becomes a fully cohesive material with liquid-saturated pores at $F s=0.99$. Table VI gives the material parameters for Eq. [2].

The variation of $C$ is shown in Figure 13. It can be seen that under solidification conditions, the solid skeleton is less connected for intermediate solid fractions, which underlines again that more liquid films are present in this solid fraction range compared with melting conditions.

\section{E. Microsuperplasticity Phenomenon}

At the lowest displacement rate, long and thin filaments (Figures 5 and 8) are present on the fracture surfaces. This type of fracture surface was previously observed in superplastically deformed aluminum

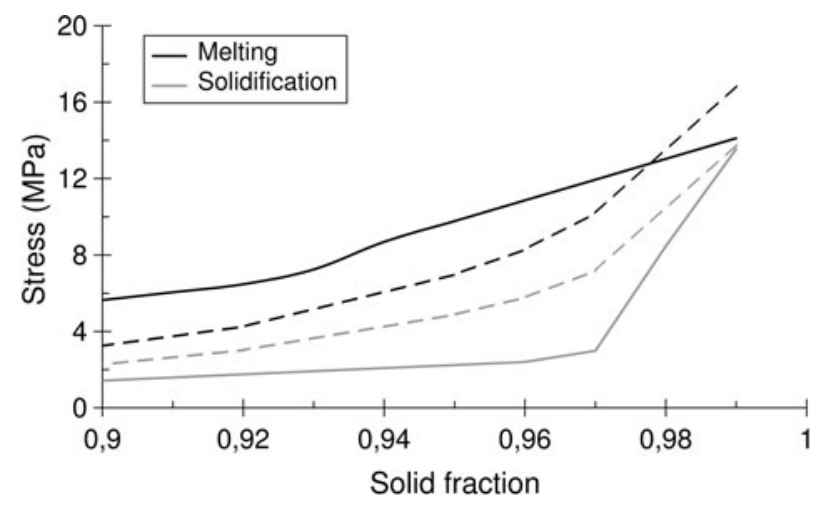

Fig. 11-Peak stress-solid fraction curves under melting (black) and solidification (gray) conditions, determined experimentally (continuous lines) and by Eq. [1] with the $F_{\mathrm{LGB}}$ values proposed by Wray (dashed lines).

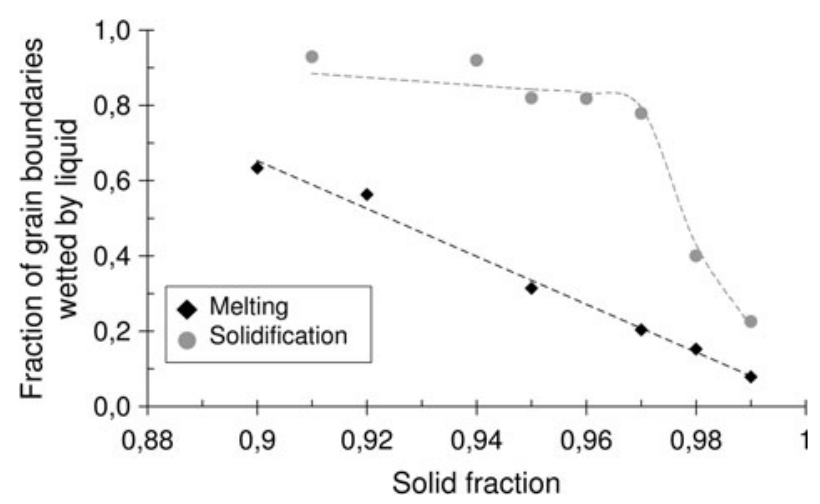

Fig. 12-Variation with solid fraction of the area fraction of grain boundaries wetted by the liquid for melting and solidification conditions. 
Table VI. Values of the Material Parameters for Equation [2]

\begin{tabular}{lcc}
\hline Type of Test & $s_{0} /\left(\dot{\varepsilon}_{0}\right)^{1 / n}\left(\mathrm{MPa} \cdot \mathrm{s}^{1 / n}\right)$ & $n$ \\
\hline Melting & 27.9 & 9 \\
Solidification & 31.6 & 6 \\
\hline
\end{tabular}

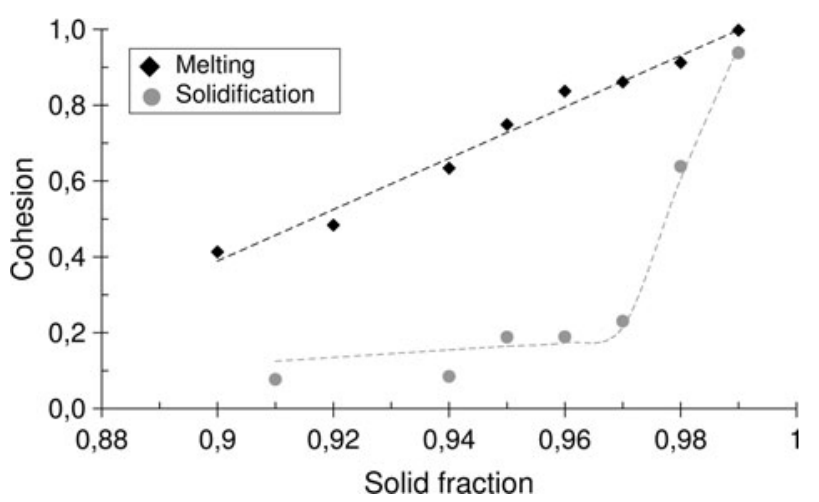

Fig. 13-Variation with solid fraction of the cohesion of the solid phase for melting and solidification conditions.

alloys. ${ }^{[25-28]}$ The authors related the formation of these thin filaments to a micro-superplasticity phenomenon involving high local deformation. This phenomenon has been linked to three possible deformation mechanisms: ${ }^{[25]}$ viscous flow, single crystalline plasticity, or superplastic flow in microvolumes, but the first one was predominantly invoked to explain the formation of filaments, ${ }^{[26-28]}$ i.e., the viscous flow of liquid or semiliquid grain boundary material. This explanation seems to be fully valid in the case of the deformation of alloys in semisolid state obtained both by partial solidification and melting. In addition, filaments form only at the lowest displacement rate, which is consistent with the observations carried out in superplastically deformed materials, showing that their length increases with decreasing strain rate. If the displacement rate is too large, viscous flow becomes unstable and filaments cannot form. Finally, it has been reported that a high concentration of oxygen and alloy elements is found in the filaments. ${ }^{[25]}$ Therefore, it is possible that oxidation plays a major role in stabilizing the filaments as soon as they form by generating a very thin oxide layer around the filaments.

\section{CONCLUSIONS}

The mechanical behavior in tension of an AA6061 alloy in the mushy state has been investigated after two different thermal paths: partial melting and partial solidification. In both cases, the mechanical response of the mushy alloy depends very much on the liquidphase morphology, which can be in the form of films or pockets. The transition between the two liquid morphologies leads to a minimum ductility related to relatively brittle fracture in the semisolid state. This transition corresponds to the larger hot cracking sensitivity of the alloy. A surprising impact of the strain rate on ductility has been found; i.e., it increases with increasing strain rate. This result seems to be linked to an increased density of cracks close to the fracture zone, leading to a less localized deformation and thus to a higher ductility. It also has been shown that the thermal path and the cooling rate during solidification strongly influence the mechanical behavior by primarily influencing the area fraction of grain boundaries wetted by the liquid or the cohesion of the solid network at a given solid fraction. A variation with solid fraction of these parameters has been proposed to describe the mechanical behavior of the semisolid state under both cases: melting and solidification. Finally, a micro-superplasticity phenomenon has been observed at the lowest strain rate with the formation of thin filaments on the fracture surfaces attributed to the viscous flow of the remaining liquid stabilized by oxidation.

\section{ACKNOWLEDGMENTS}

One of the authors (EG) is grateful to CNRS (French National Center for Scientific Research) for financial support through a scholarship. The authors thank Cédric Gasquères, ALCAN CRV, for providing the ProPhase calculations.

\section{REFERENCES}

1. R.F. Muraca and J.S. Whittick: Materials Data Handbook, 2nd ed., Western Applied Research and Development Inc., San Carlos, CA, 1972.

2. D.G. Eskin, Suyitno, and L. Katgerman: Prog. Mater. Sci., 2004, vol. 49 , pp. 629-711.

3. D.G. Eskin and L. Katgerman: Metall. Mater. Trans. A, 2007, vol. 38A, pp. 1511-19.

4. W.M. van Haaften, W.H. Kool, and L. Katgerman: Mater. Sci. Forum, 2000, vols. 331-337, pp. 265-70.

5. M.R. Twite, J.A. Spittle, and S.G.R. Brown: Int. J. Form. Proc., 2004, vol. 7, pp. 233-60.

6. D. Fabrègue, A. Deschamps, M. Suéry, and W.J. Poole: Metall. Mater. Trans. A, 2006, vol. 37A, pp. 1459-67.

7. M.G. Chu and A. Granger: Mater. Sci. Forum, 1996, vols. 217222, pp. $1505-10$.

8. W.M. van Haaften, W.H. Kool, and L. Katgerman: Mater. Sci. Eng., 2002, vol. 336A, pp. 1-6.

9. H. Nagaumi, Takateru, and Umeda: Mater. Sci. Forum, 2003, vols. 426-432, pp. 465-70.

10. A.K. Dahle, S. Instone, and T. Sumitomo: Metall. Mater. Trans. $A, 2003$, vol. 34 A, pp. $105-13$.

11. E. Tzimas and A. Zavaliangos: Acta Mater., 1999, vol. 47, pp. 517-28.

12. O. Ludwig, J.M. Drezet, C.L. Martin, and M. Suéry: Metall. Mater. Trans. A, 2005, vol. 36A, pp. 1525-35.

13. O. Ludwig, J.M. Drezet, P. Ménésès, and M. Suéry: Mater. Sci. Eng., 2005, vols. 413-414A, pp. 174-79.

14. W.M. van Haaften, B. Magnin, W.H. Kool, and L. Katgerman: Metall. Mater. Trans. A, 2002, vol. 33A, pp. 1971-80.

15. B. Magnin, L. Maenner, L. Katgerman, and S. Engler: Mater. Sci. Forum, 1996, vols. 217-222, pp. 1209-14

16. D.J. Lahaie and M. Bouchard: Metall. Mater. Trans. B, 2001, vol. 32B, pp. 697-705.

17. M. Rappaz, J.M. Drezet, and M. Gremaud: Metall. Mater. Trans. A, 1999, vol. 30A, pp. 449-55. 
18. J.E. Hatch: Aluminum: Properties and Physical Metallurgy, ASM, Metals Park, OH, 1984, pp. 58-104.

19. C. Sigli, L. Maenner, C. Sztur, and R. Shahani: Proc. 6th Int. Conf. on Aluminum Alloys, T. Sato, S. Kumai, T. Kobayashi, and Y. Murakami, eds., JILM, Tokyo, 1998, pp. 87-98.

20. S. Terzi, L. Salvo, M. Suéry, N. Limodin, J. Adrien, E. Maire, Y. Pannier, M. Bornert, D. Bernard, M. Felberbaum, M. Rappaz, and E. Boller: Scripta Mater., 2009, vol. 61, pp. 449-52.

21. A.K. Dahle and L. Arnberg: JOM, 1996, vol. 48, pp. 34-37.

22. B.S. Bokstein: Mater. Sci. Forum, 1996, vols. 217-222, pp. 685-88.
23. X. Doré, H. Combeau, and M. Rappaz: Acta Mater., 2000, vol. 48, pp. 3951-62.

24. P.J. Wray: Acta Metall., 1975, vol. 24, pp. 125-33.

25. M.G. Zelin: Acta Mater., 1997, vol. 45, pp. 3533-42.

26. Y. Takayama, T. Tozawa, and H. Kato: Acta Mater., 1999, vol. 47, pp. 1263-70.

27. J.J. Blandin, B. Hong, A. Varloteaux, M. Suéry, and G. L'Esperance: Acta Mater., 1996, vol. 44, pp. 2317-26.

28. W.D. Cao, X.P. Lu, and H. Conrad: Acta Mater., 1996, vol. 44, pp. $697-706$ 